\title{
Factores que influyen en la inasistencia de las mujeres embarazadas a la atención odontológica durante los controles prenatales en seis centros de salud de primer nivel en Cercado, Cochabamba, Bolivia
}

Factors that influence the non-attendance of pregnant women to the dentist during the prenatal controls On six first level Health centers in Cochabamba

\author{
Violeta Veliz Vaca ${ }^{1}$
}

\begin{abstract}
Resumen
Objetivo: analizar los factores que influyen en la inasistencia a la atención odontológica, de las gestantes que realizan controles prenatales en el Municipio de Cercado, Cochabamba. Material y métodos: se realizó un estudio descriptivo transversal, los sujetos de estudio fueron 9 médicos, 9 odontólogos y 810 gestantes que acudieron a controles prenatales, en seis centros de primer nivel en la zona sur y norte. Fuente de información: historias clínicas durante el primer semestre de la gestión 2017. Se realizó análisis univariado y bivariado empleando: $X^{2}, P, I C 95 \%$, RR.OR. Resultados: gestantes no acuden a la atención odontológica por los siguientes factores: Viven lejos del centro de salud: $X^{2}=12 P=0,0003(I C 95 \%=1,05-1,21) . R R=1,12 \cdot 0 R=1,86$. No consideran importante la salud oral durante el embarazo, dan calificación baja a la importancia de acudir al dentista durante el embarazo: $X^{2}=8,65 P=0,001($ IC95\% $=1,04-1,19)$. $R R=$ $1,11 . \mathrm{OR}=1,85$. Miedo de ir al dentista por creencias culturales, citan malformaciones en el feto, aborto, desmayos: $X^{2}=47,05 P=0,0000$. (IC95\% 1,18 - 1,37). $R R=1,27.0 R=3,66$. No saben que la atención dental en el embarazo es gratuita: $X^{2}=66,36 P=0,0000$. (IC95\%1,27$1,41) \cdot R R=1,34$. $O R=17,74$. No fueron derivadas para interconsulta con el odontólogo, durante los controles prenatales: $X 2=92,61 P=$ 0,0000. (IC95\%1,34-1,68).RR=1,50.OR=5,61. Desconocimiento de la atención dental en el embarazo, cuando hay patología dental: $X^{2}$ $=207 \mathrm{P}=0,000000(\mathrm{IC} 95 \%=1,56-1,90) . \mathrm{RR}=1,72 . \mathrm{OR}=25,89$. Conclusiones: los factores que influyen negativamente en la asistencia de las gestantes a la atención odontológica, son aspectos culturales, accesibilidad geográfica, relación médico paciente establecida en consulta prenatal y odontológica.
\end{abstract}

Palabras claves: factores, asistencia, atención odontológica, embarazo.

\section{Abstract}

Objectives: to analyze the factors that influence the non-attendance to the dental care of the pregnant women who perform prenatal checks in the Municipality of Cercado, Cochabamba. Methods: a cross-sectional descriptive study was made; the study subjects were 9 physicians, 9 dentists and 810 pregnant women who attended prenatal control in six first level centers in the south and north. Source of information: clinical histories in the first semester of the 2017 administration. Univariate and bivariate analysis were performed using: $X^{2}$, P, 95\% Cl, RR.OR. Results: pregnant women do not attend dental care due to the following factors: They live far from the health center, $\mathrm{X}^{2}=12 \mathrm{P}=0.0003(\mathrm{IC} 95 \%=1.05-1.21) . \mathrm{RR}=1.12 . \mathrm{OR}=1.86$. They do not consider oral health important during pregnancy, they give low rating to the importance of going to the dentist during pregnancy: $X^{2}=8.65 P=0.001(95 \% \mathrm{Cl}=1.04-1.19)$. $R R=1,11.0 R=1,85$. Fear of going to the dentist for cultural beliefs, cite malformations in the fetus, abortion, fainting: $X^{2}=47.05 \mathrm{P}=0.0000 .(95 \% \mathrm{Cl} 1.18-1.37)$. $\mathrm{RR}=1,27 . \mathrm{OR}=3,66$. They do not know that dental care in pregnancy is free: $\mathrm{X}^{2}=66.36 \mathrm{P}=0.0000 .(95 \% \mathrm{Cl} 1.27-1.41) . \mathrm{RR}=1.34 . \mathrm{OR}=$ 17.74. They were not referred to interconsultation with the dentist, during prenatal checks: $X^{2}=92.61 \mathrm{P}=0.0000 .(95 \% \mathrm{Cl} 1.34-1.68)$. $R R$ $=1.50 .0 R=5.61$. Unawareness of dental care in pregnancy, when there is dental pathology: $X^{2}=207 \mathrm{P}=0.000000($ IC95\% $=1.56-1.90)$. $\mathrm{RR}=1.72 . \mathrm{OR}=25.89$. Conclusions: the factors that negatively influence the attendance of pregnant women to dental care are: cultural aspects, geographic accessibility, patient medical relationship established in prenatal and dental consultation.

Keywords: factors, care, dental care, pregnancy.

$\mathrm{E}$ 1 Seguro Integral de Salud en Bolivia es una estrategia de aseguramiento universal que busca reducir la mortalidad y morbilidad materna infantil ${ }^{1}$. Este seguro facilita el acceso a las mujeres embarazadas para su atención médica y odontológica en los servicios de salud del sistema estatal. Sin embargo pese a haber eliminado la barrera económica y ofertar prestaciones odontológicas durante el embarazo, que benefician al binomio madre niño, existen bastantes mujeres gestantes que no acuden al servicio odontológico. La utilización de servicios no se da en forma homogénea en la población gestante, esto depende de la

${ }^{1}$ Cirujano Dentista. Universidad Técnica Privada Cosmos, Cochabamba, Bolivia. ${ }^{*}$ Correspondencia a: Violeta Veliz Vaca

Correo electrónico: jambaov3@hotmail.com

Recibido el 09 de octubre del 2017. Aceptado el 20 de enero del 2018. combinación de diferentes aspectos que se relacionan con las características de las gestantes, las necesidades presentes y las condiciones de acceso a los servicios ${ }^{2}$.

Las enfermedades orales constituyen un problema importante de salud pública. La razón de ello es su alta prevalencia, por la demanda pública y su impacto sobre las personas en la sociedad en términos de: dolor, malestar, limitación, y minusvalía social y funcional así como su efecto sobre la calidad de vida. El Ministerio de Salud y Deportes, revelan la amplitud y severidad del problema que sufre la mayoría de la población Boliviana; indicando que el 95\% padece de caries dental, y la prevalencia de caries no tratadas alcanza al $84,6 \%^{3}$.

Los padecimientos más frecuentes en Salud Oral son 
caries y enfermedad periodontal, según la OMS casi el $100 \%$ de los adultos tienen caries dental en todo el mundo ${ }^{4}$, y las enfermedades periodontales graves, afectan $15-20 \%$ de adultos de edad media (35-44 años) ${ }^{4}$.

En las gestantes es posible observar mayor frecuencia de lesiones de tejidos blandos como gingivitis gravídica con prevalencia de 25 a $100 \%$ por los cambios hormonales asociada a la acumulación de placa bacteriana, cálculo dental ${ }^{5,6}$.

En Bolivia y en otros países, además de ser una población vulnerable a estas patologías orales, existen distintos factores que influyen en la asistencia de la gestante a consulta dental, relegando la atención odontológica durante el embarazo. Diferentes investigaciones demuestran que existen creencias culturales en torno al embarazo y salud oral. Se menciona generalmente la creencia arraigada en las gestantes de que no deben recibir atención odontológica por el efecto dañino que puede ocasionar el empleo de materiales dentales al feto ${ }^{5}$.

Las gestantes perciben cambios en la salud oral durante el embarazo de forma diferente, dependiendo de factores socioculturales en los que viven ${ }^{2}$.

En Bolivia la asistencia de la gestante al control prenatal está asociado al Bono Juana Azurduy, bono de lactancia materna, y al Servicio Integral de Salud. Sin embargo no hay mecanismos además del Servicio Integral en Salud que motiven a la gestante a acudir al servicio dental.

Un modelo explicativo sobre el uso de servicios odontológicos, propuesto por Andersen ${ }^{2}$ tomado en cuenta para el estudio fueron:

a) Variables predisponentes: características sociodemográficas que condicionan la mayor probabilidad de utilizar los servicios. Se incluyen edad, sexo, estado civil, educación. También se consideran creencias y actitudes sobre la enfermedad $^{2}$.

b) Variables facilitadoras: pueden impedir o facilitar el uso de los servicios. Entre ellas acceso a algún seguro de salud, accesibilidad geográfica y aspectos relacionados con la organización del servicio de salud como relación médico paciente ${ }^{2}$.

\section{Material y métodos}

Se realizó un estudio descriptivo transversal, los sujetos de estudio a encuestar fueron nueve médicos, nueve odontólogos y 810 gestantes que acudieron a controles prenatales, en seis centros de primer nivel en la zona sur y norte, en el primer semestre de la gestión 2017.

Los criterios de inclusión fueron: Mujeres con dos o más controles prenatales. Médicos y odontólogos, con una antigüedad mayor a un año en los servicios de salud primarios.

Los criterios de exclusión fueron: mujeres en edad fértil que no estén embarazadas, mujeres que no deseen participar en el estudio, mujeres con menos de dos controles prenatales. médicos y odontólogos con una antigüedad menor a un año en los servicios de salud primarios.

Otras fuentes de información adicional para recolección de datos epidemiológicos y tratamientos odontológicos en gestantes, incluyen 574 historias clínicas y cuadernos odontológicos del Sistema Nacional de Información en Salud.

El método de muestreo fue selección por conveniencia en gestantes que tenían dos o más controles prenatales para la encuesta en los seis centros de primer nivel de atención elegidos en Cercado, Cochabamba en la gestión 2017. Se aplicó muestreo aleatorio simple en la revisión de historias clínicas, en base a la población de embarazos esperados en el centro de salud seleccionado, entre el tamaño de muestra, para conseguir la constante $\mathrm{K}$. La lista de gestantes son las que recogieron su subsidio, porque son gestantes que se encuentran con más de dos controles prenatales.

El análisis de la información: estadística descriptiva, puesto que el primer paso del análisis de los datos consiste en describirlos. Después se aplicó la estadística descriptiva bivariada empleando " $\mathrm{X}^{2}$, P, IC 95\%, RR, OR" para la búsqueda de la relación que hay entre las variables que se cruzan, con un nivel de significación estadística de 0,05 o 5\%.

\section{Resultado}

Los resultados respecto a los factores sociodemográficos de las gestantes incluidas en el estudio, no se encontró asociación con la inasistencia a la atención dental durante el embarazo.

Los factores culturales que si influyen en la inasistencia de las gestantes a la atención dental durante el embarazo, con significancia estadística son: "no le dan importancia a la salud oral por la baja puntuación que le dan a la importancia de la atención dental, miedo a asistir al dentista, desconocimiento del servicio dental gratuito, desconocimiento de la atención dental durante el embarazo en presencia de patología dental" (Tabla 1).

Los factores facilitadores para la inasistencia dental durante el embarazo, con significancia estadística son: "accesibilidad geográfica”, las que viven lejos del centro de salud, o en otro barrio. Respecto a la "relación médico gestante en los centros de salud", las gestantes que no son remitidas al servicio odontológico, cuando asisten al control prenatal (Tabla 1).

\section{Discusión}

Los factores sociodemográficos, no demostraron asociación estadística para ser considerados factores de riesgo en la atención dental durante el embarazo.

Considerando las percepciones de las gestantes sobre la importancia de la atención dental durante el embarazo, el $66,54 \%$ de las gestantes asignan una puntuación alta entre 6-10 a la importancia de la atención dental en esta etapa, con una mediada de 5. Aun así, las gestantes que asisten al dentista durante el embarazo representan el 19,63\%.

Más de la mitad de las gestantes de este estudio perciben cambios en su salud bucal durante el embarazo; entre ellos el sangrado de las encías y aún así la cantidad de gestantes que acuden al servicio dental representan la quinta parte de las que perciben cambios. Resultados similares presentan Álvarez Calle , 2008; Marc y Col. 2010; Miraschi y col.20097-9.

A pesar de que el $63,21 \%$ de las gestantes admite tener tiempo para acudir al dentista, el 80,37 no lo hace, lo que nos hace pensar que son otros los factores por los que no 
Tabla 1. Análisis bivariado de factores predisponentes y facilitadores en la población de estudio que influyen en la inasistencia a la atención odontológica, en los centros de salud.

\begin{tabular}{|c|c|c|c|c|c|c|c|}
\hline VARIABLE & $\begin{array}{l}\text { \% NO } \\
\text { ACUDEN }\end{array}$ & $\begin{array}{l}\% \\
\text { ACUDEN }\end{array}$ & OR & IC & RR & $P$ & IC \\
\hline $\begin{array}{l}\geq 13-26 \text { años } \\
\geq 27-49 \text { años }\end{array}$ & $\begin{array}{l}80,09 \\
80,67\end{array}$ & $\begin{array}{l}19,91 \\
19,33\end{array}$ & 0,96 & $0,68-1,36$ & 0,99 & 0,453583 & $0,92-1,06$ \\
\hline $\begin{array}{l}\text { Sin pareja estable } \\
\text { Pareja estable }\end{array}$ & $\begin{array}{l}81,76 \\
80,00\end{array}$ & $\begin{array}{l}18,24 \\
20,00\end{array}$ & 1,12 & $0,72-1,73$ & 1,02 & 0,346293 & $0,94-1,10$ \\
\hline $\begin{array}{l}\text { Bajo grado de instrucción } \\
\text { Alto grado de instrucción }\end{array}$ & $\begin{array}{l}84,27 \\
79,27\end{array}$ & $\begin{array}{l}15,73 \\
20,73\end{array}$ & 1,40 & $0,89-2,19$ & 1,06 & 0,082523 & $0,98-1,14$ \\
\hline $\begin{array}{l}\text { Buen ingreso económico } \\
\text { Bajo ingreso económico }\end{array}$ & $\begin{array}{l}80,75 \\
80,09\end{array}$ & $\begin{array}{l}19,25 \\
19,91\end{array}$ & 1,04 & $0,73-1,48$ & 1,00 & 0,443384 & $0,94-1,07$ \\
\hline $\begin{array}{l}\text { Vivienda lejos del centro de salud } \\
\text { Vivienda cerca del centro de salud }\end{array}$ & $\begin{array}{l}85,04 \\
75,32\end{array}$ & $\begin{array}{l}14,96 \\
24,68\end{array}$ & 1,86 & $1,30-2,65$ & 1,12 & 0,000344 & $1,05-1,21$ \\
\hline $\begin{array}{l}\leq 1-5 \text { puntuación importancia } \\
\geq 6-10 \text { puntuación importancia }\end{array}$ & $\begin{array}{l}86,35 \\
77,37\end{array}$ & $\begin{array}{l}13,65 \\
22,63\end{array}$ & 1,85 & $1,23-2,76$ & 1,11 & 0,001332 & $1,04-1,19$ \\
\hline $\begin{array}{l}\text { No notan cambios orales } \\
\text { Si notan cambios orales }\end{array}$ & $\begin{array}{l}83,53 \\
79,15\end{array}$ & $\begin{array}{l}16,44 \\
20,85\end{array}$ & 1,34 & $0,89-2,00$ & 1,05 & 0,092751 & $0,98-1,13$ \\
\hline $\begin{array}{l}\text { Tienen miedo } \\
\text { No tienen miedo }\end{array}$ & $\begin{array}{l}89,62 \\
70,21\end{array}$ & $\begin{array}{l}10,38 \\
29,79\end{array}$ & 3,66 & $2,50-5,36$ & 1,27 & 0,000000 & $1,18-1,37$ \\
\hline $\begin{array}{l}\text { No sabe qué la atención es gratis } \\
\text { Sabe que la atención es gratis }\end{array}$ & $\begin{array}{l}97,94 \\
72,84\end{array}$ & $\begin{array}{l}2,06 \\
27,16\end{array}$ & 17,74 & $7,18-43,86$ & 1,34 & 0,000000 & $1,27-1,41$ \\
\hline $\begin{array}{l}\text { No son derivadas } \\
\text { Son derivadas }\end{array}$ & $\begin{array}{l}89,04 \\
59,15\end{array}$ & $\begin{array}{l}10,96 \\
40,85\end{array}$ & 5,61 & $3,88-8,11$ & 1,50 & 0,000000 & $1,34-1,68$ \\
\hline $\begin{array}{l}\text { No sabe que debe realizar atención } \\
\text { dental }\end{array}$ & $\begin{array}{l}97,08 \\
56,19\end{array}$ & $\begin{array}{l}2,92 \\
43,81\end{array}$ & 25,89 & $14,6-45,98$ & 1,72 & 0,000000 & $1,56-1,90$ \\
\hline
\end{tabular}

Fuente: Elaboración propia. Epi Info 7.2.0.1

asisten. Un hallazgo importante es el miedo de las gestantes para recibir atención odontológica, indicando el daño que puede producir al feto o desmayos durante los tratamientos. Similares resultados describen Guerra Me et al., 2011; Fuentes Fernández R. et al., 2009; Garbero I. et al., 2005 5,10,11.

A pesar del tiempo de vigencia que ha tenido el Seguro Universal Materno Infantil en el país, actualmente Seguro Integral Salud; se identificó gestantes que desconocen la gratuidad de la atención dental durante el embarazo. Similar resultado presenta Álvarez Calle, $2008^{7}$.

La relación que elabora la embarazada entre su estado gestante y la condición bucodental está influenciada por sus creencias tradicionales y prácticas culturales. Entre ellas cuando existen patologías dentales durante el embarazo, hay gestantes que indican que no se debe realizar atención odontológica durante el embarazo o no saben y prefieren soportar la sintomatología hasta después del parto. Lo anterior, coincide con trabajos de investigación de Juan Antonio Córdova et al. 2007 2 .

Los servicios de salud tienen una oferta de prestaciones para las mujeres gestantes que esta establecido en el paquete de las prestaciones de la Ley 475. La revisión de las 574 historias clínicas y en el informe mensual de actividades odontológicas del primer semestre, mostró que las actividades de educación en salud oral para la gestante, son descuidadas por parte de los odontólogos. Las prestaciones odontológicas son curativas restaurativas en su mayoría. El motivo de consulta es en 52,75\% dolor o molestia, donde el odontólogo necesita emplear materiales químicos para la atención de su patología, generando desconfianza en las gestantes que no desean recibir atención odontológica por el daño que podría producir al feto los tratamientos y uso de anestésicos locales. No se considera al control odontológico durante el embarazo como parte integral del cuidado para la madre y del niño. Las profilaxis dentarias que se efectúan en los servicios dentales y algunas actividades de prevención y educación en salud oral no denota el impacto preventivo que debería existir en las gestantes $^{13}$.

El $66,67 \%$ de los odontólogos, mencionan que prefieren realizar la atención posterior al parto, exponiendo que pueden solicitar exámenes complementarios como radiografías dentales y que las gestantes están menos ansiosas. El odontólogo debe estar capacitado para explicar que la dosis de radiación requiere una exposición muy baja y no causa daño (por seguridad empleamos el mandil de plomo) y los medicamentos penicilina, paracetamol y anestésicos tipo amida (lidocaína), no tienen repercusión materna ni fetal ${ }^{14,15}$.

Se observó que el tiempo empleado en el control prenatal independientemente de ser el primero, es de 15 minutos. Según aumenta la cantidad de gestantes los médicos tienen menos tiempo dedicado a consulta, por tanto tienden a obviar actividades establecidas en consulta prenatal afines a la salud oral. Más del $50 \%$ de los médicos indican que no realizan el examen oral de manera rutinaria. La consulta de sintomatología en la cavidad oral tampoco se realiza rutinariamente. En la revisión de 574 historias clínicas, solo el 9\% registra la inspección dental en el CLAP.

\section{Conclusiones y recomendaciones}

Los factores culturales que influyen en la inasistencia a la atención dental durante el embarazo con significancia 
estadística son: "la baja puntuación que le dan a la importancia de la atención dental, miedo a asistir al dentista, desconocimiento del servicio dental gratuito, y el desconocimiento de la atención dental durante el embarazo en presencia de patología dental".

Los factores considerados facilitadores para la inasistencia dental durante el embarazo, con significancia estadística son: "accesibilidad geográfica", para las que viven lejos del centro de salud, o en otro barrio. Respecto a la "relación médico gestante en los centros de salud", las gestantes que no son remitidas al servicio odontológico, cuando asisten al control prenatal. La atención integrada al continúo del curso de la vida, indica referir a la gestante al odontólogo, en presencia de caries, gingivitis, periodontitis ${ }^{16}$. Se consultó a médicos, gestantes y se revisó historias clínicas; donde casi la totalidad de gestantes no son remitidas a interconsulta con el odontólogo. Esta falta de coordinación entre profesionales, también se menciona en estudios de Guerra me et al., 2011; Garbero I. et al., 2005,10.

En la "relación odontólogo gestante en los centros de salud", el manual de normas en salud oral, establece la prevención de enfermedades orales consideradas problemas de salud pública tempranamente, comenzando por el periodo de gestación a través de uso de métodos educativos y preventivos. Sin embargo no se la aplica al pie de la letra, según se evidencia en la revisión de historias clínicas y el informe mensual de actividades odontológicas.

La gestante tiene conocimiento limitado acerca del control odontológico durante el embarazo, por tanto la patología más frecuente por la cual acuden al servicio dental es caries dental.

Hace falta una atención integrada en la gestante que promueva y verifique la atención dental en ellas; para que no quede estrictamente en función a su decisión. Teniendo en cuenta que se espera más de dos horas para conseguir una ficha dental, disponiendo solo entre cuatro a cinco fichas de atención.

El odontólogo no es el único responsable para que la gestante acceda a la atención dental durante el embarazo, sin embargo, se deben generar estrategias y/o actividades que promocionen la atención odontológica de las gestantes dentro y fuera del centro de salud. La importancia de actividades de promoción en salud oral, implica la información transmitida para orientarla y también por el efecto multiplicador de la información transmitida.

Conflictos de interés: los autores declaramos que no existe conflicto de intereses.

\section{Referencias bibliográficas}

1. Ministerio de Salud y Deportes: Manual de Normas en Salud Oral. Bolivia. 2006. 221 p. Viceministerio de Politicas de Salud Direccion de Regulacion y Legislacion en Salud.

2. Lara F. Norma, Lopez C. Victor. Factores que influyen en la utilizacion de servicios odontologicos. Rev la Asoc Dent Mex. [Internet].2002;LIX, No. 3:pp 100 - 9. Disponible en : http://www.medigraphic.com/pdfs/adm/od2002/od023e.pdf

3. Ministerio de Salud y Deportes: Manual de Normas en Salud Oral.Bolivia.No 2. Normativo documento T, editor. Bolivia: Ministerio de salud y deportes; 2006. $220 \mathrm{p}$.

4. OMS. Salud bucodental. OMS[Internet]. 2012;318. Citado 20 jul 2017. Available from:http:// www.who.int/Medicacentre/Factsheets/fs318/es/

5. Garbero I, Delgado M, Benedito L. Salud oral en embarazadas: Conocimientos y Actitudes. Rev. Acta odontológica Venez. [Internet]. 2005. ISNN 0001 - 6365. 1-10. Disponibleenhttp://www. actaodontologica.com/ediciones/2005/2/salud_ oral_embarazadas.asp?print=true

6. Martinez L, Salazar C, Ramirez G. Estrato social y prevalencia de gingivitis en gestantes, Estado Yaracuy, Municipio San Felipe . Rev. Acta odontológica Venez. [Internet] [cited 2017Aug23]. Disponible:https://www.actaodontologica.com/ ediciones/2001/1/estrato_social_prevalencia_ gingivitis.asp

7. Alvarez C.Walter. Creencias Culturales que intervienen en la practica de Salud Oral en gestantes en el hospital "Virgen del Rosario" Municipio El Villar Gestion 2008. Universidad Mayor de San Andrés; 2008. Bolivia. [Internet]. Disponible en: http://repositorio.umsa.bo/ bitstream/handle/123456789/3673/TPG677. pdf? sequence $=1$ \&isAllowed $=y$

8. Constanza S, Sánchez C. La salud Oral de las mujeres gestantes, sus repercusiones y los aspectos que influencian su atencion. Rev UstaSalud [Internet]. 2011 [cited 2017 Jul 18];10:110126. Disponible:http://revistas.ustabuca.edu.co/index. php/USTASALUD_ODONTOLOGIA/article/ viewFile/1142/937

9. Miraschi C, Ríos M, Urzúa JP BP. Calidad de vida y condición de salud oral en embarazadas chilenas e in- migrantes peruanas. RevPerú Med Exp Salud Pública. 2009;26:pp45561.[Internet]. Disponibleen:http://www.scielo.org.pe/scielo. php?pid $=\$ 1726-46342009000400007 \&$ script $=$ sci arttext

10. Guerra Me; Tovar V; Blanco L., Gutierrez H. Informacion sobre salud bucal a embarazadas en la consulta prenatal del ambulatorio docente del hospital Universitario deCaracas. ActaOdontolVenez.[Internet].2011[cited2016Nov 21];VOLUMEN49.

Disponible en:http://www.actaodontologica.com/ ediciones/2011/2/art7.asp

11. Fuentes F.R, Oporto V.G, Alarcón A.M, Bustos M. L, Prieto G. R. Rico W.H. Opiniones $y$ creencias de embarazadas en control prenatal relacionadas con salud oral y embarazo. Av
Odontoestomatol [Internet]. 2009 [cited 2017 Aug 23];25(3):147-54.Disponible en: http:// scielo.isciii.es/scielo.php?script=sci_arttext\&pid =S0213-12852009000300004

12. Córdova H. J.A, Bulnes L. Rosa. Nivel de conocimiento sobre prevención de salud bucal en gestantes, hospital de la mujer, Villahermosa, Tabasco 2007. Rev.Horiz Sanit ISSN 2007;6,[Internet].pp:18_25.Disponibleen:http:// www.redalyc.org/articulo.oa?id=457845049001

13. Ayala de la Vega G. Centro de Salud Carmen de la Legua Reynoso - Callao 2001. Universidad Nacional Mayor De San Marcos; 2004.Peru. [Internet]. Disponible en: http://cybertesis. unmsm.edu.pe/bitstream/cybertesis/2757/1/ Ayala_vg.pdf

14. Fernández G. O, Chávez M. M. Atención odontológica en la mujer embarazada. Arch. Invetigacionesmaternoinfantiles. Mayo. Agosto.2010;II(2):80_4. [Internet].

Disponibleen:http://www.medigraphic.com/ maternoinfantil/

15. Llodra. C. J.C. Salud oral y embarazo 120705. indd. [cited 2017 Jul 18]; [Internet].Available from: http://www.saludoralyembarazo.es/assets/ pdf/guia.pdf

16. Calvimontes D.M. Atencion Integrada al Continuo Del curso la Vida.Parte II Mujeres en edad fertil - mujer durante el embarazo, parto y puerperio. Deportes. M de S y, editor. La Paz, Bolivia; 2013. 23-77 p. 